Anderson, J. A. D., 1978. "Working Group on Low Back Pain", Fac.Comm.Med. RCP Newletter 5, 72-9.

Hume-Kendall, P. and Jenkins, J. M., 1968a. “Lumbar Isometric Flexion Exercises”, Physiotherapy 54, 158-63. 1968b. "Exercises for Backache: A Double-Blind Controlled Trial”, Physiotherapy, 54, 154-7.

Davies, J. E. et al, 1979. "The Value of Exercises in the Treatment of Low Back Pain", Rheumatol. \& Rehabil., 18, 243-247.

\title{
DISCUSSION
}

\section{THE SPINE IN SPORT}

P. R. TRAVERS. Few people watching sport in a stadium or on television realize the high load that training produces. They may watch six shot putts or jumps without realizing the hundreds of equally good performances in training, perhaps twenty to thirty in one session, with resultant stress on the spine and limbs, a much greater stress than in competition. Distance runners will cover thousands of miles in training every year, so the production of overuse injuries is inevitable.

J. RUSHTON estimated that one shot putter making 30,000 lifts of 300 to 400 lbs. in a season in his training, is lifting weights amounting to six tons in each session.

J. E. DAVIES had reported earlier that only five of the patients seen by Billings showed injuries to the posterior apophyseal joints of the lumbar vertebral arches as opposed to thirty disc lesions. These results were questioned, as the posterior joints are structurally much weaker than the anterior ones. Disc lesions, easy to suspect, cannot always be confirmed, and a recent case of an apparently obvious disc prolapse proved at laminectomy to be a simple osteophyte whose radiological appearance was identical with a disc lesion, and with similar signs of cord compression.

Some question the frequency of muscle strains to the back, believing them to be rarer than apophyseal joint lesions. Others accept a diagnosis of muscle strain if there is a history of acute injury followed by muscle spasm, and without referred signs or symptoms.

J. G. P. WILLIAMS stated that Sullivan carried out electromyographic studies which suggested that muscle strains might occur more frequently than is generally accepted. 